\title{
Os Catalépticos e Um Fausto: Novos Mesmos Poemas
}

\section{The Cataleptics and a Faust: New Same Poems}

\author{
Adriano da Rosa Smaniotto*
}

\begin{abstract}
This paper intends to show a few of the translations of poetry made in Curitiba, Brazil, by the OSS group. The authors - Marcos Prado, Thadeu Wojciechowski, Sérgio Viralobos e Roberto Prado -have been publishing since the decade of 1980, but in the 1990s there was an enlargement in the poetic production of the group. Their translations are from this context, and they are called free adaptations or synthesis recreations. In these translations there are many characteristics from other poems also produced by them, besides the presence of aesthetics influences that sustained them. They have another perspective about the tradition, but they do not deny it: they reinvent it and reaffirm it. There is, finally, the intention of spreading this poetry, unconsumed and unknown for most people, but important for the Brazilian poetic scene.
\end{abstract}

Keywords: Translation of poetry - OSS Group - Paranaense poetry - 1990s.

Resumo: Este artigo pretende apresentar um pouco da tradução de poesia feita em Curitiba pelo grupo de autores OSS. Seus representantes - Marcos Prado, Thadeu Wojciechowski, Sérgio Viralobos e Roberto Prado - publicam desde a década de 1980, mas há na década de 1990 o aumento de sua produção poética. Nesse contexto aparecem suas traduções, entendidas como adaptações livres, ou ainda, recriaçõessíntese. Nestas traduções há muitas características comuns aos seus demais poemas, bem como a presença das influências estéticas que os sustentam. Mesmo traduzindo com outro olhar para a tradição, não a negam: reinventam-na e a reafirmam. Há, por fim, o intuito de apresentar um pouco dessa poesia, não consumida e desconhecida pelo público em geral, mas importante para a cena poética brasileira.

\footnotetext{
"Mestre em Estudos Literários/UFPR. E-mail: smaniotto@hotmail.com
} 
Palavras-chave: Tradução de poesia - Grupo OSS - Poesia Paranaense - Década de 1990.

TradTerm, São Paulo, v. 21, julho/2013, p. 131-145

www.usp.br/tradterm 


\section{Os Catalépticos}

Há muita poesia feita em Curitiba na década de 1990. A gama de autores divide-se entre aqueles que já publicavam nos anos 80 - Paulo Leminski, Thadeu Wojciechowski, Marcos Prado, Roberto Prado, Edson de Vulcanis, Sergio Viralobos, Alice Ruiz, o grupo Encontrovérsia, para mencionar alguns - e novos poetas que surgem impulsionados em grande parte pelo alcance da obra leminskiana; ou mesmo, pelo fomento de eventos municipais em torno da literatura como o Perhappines, bem como pelo diálogo cultural com outras manifestações artísticas: como o proporcionado por algumas bandas de Rock, que conciliaram música e letras de protesto, estas muitas vezes entendidas como poesia.

Por ora, não entrarei no mérito de uma discussão valorativa, tampouco na relevância de tal década para a poesia. Prefiro me situar em duas obras específicas do período em questão, Os Catalépticos e Um Fausto, as quais suscitam um olhar diferente sobre a tradução literária ao passo que trazem intrínsecas algumas das concepções de poesia vigentes nos anos 1990.

Publicado em 1991, o livro Os Catalépticos difere de outras produções porque não é assinado por um autor, mas por quatro autores: Thadeu Wojciechowski, Marcos Prado, Roberto Prado e Sergio Viralobos ${ }^{1}$. Há poemas em que a produção pertence aos quatro, outros em que participam três, dois autores; de modo que o processo criativo se torna bastante democrático e abrangente, afinal não se trata de apenas um, mas quatro indivíduos trabalhando em parceria. Tal prática se assemelha, em partes, a uma oficina de tradução e criação, onde as ideias tramitam e transitam, propondo melhores soluções em virtude do diálogo engendrado para tal fim. Se pensarmos o quanto o estatuto do autor representa numa publicação, estamos

Há no poema "O corvo" a participação do poeta Edilson del Grossi, citado no crédito da tradução, porém não no crédito total da obra, acredito que em virtude da presença dos demais autores em mais de uma tradução. 
diante de uma atitude estética no mínimo menos elitista e mais democrática, porque não apoiada no teor de verdade que a autoria representa. Entretanto, o que interessa no momento é a proposta de tradução literária que esta “poesia a quatro mãos" propõe, percebida na introdução da obra:

\footnotetext{
Os catalépticos são os que morrem e, algum tempo depois, voltam. Normalmente eles são enterrados vivos. Pretendemos, com esta obra, não só enterrá-los mais uma vez como também fazê-los rir a mortalhas despregadas. Não se fala aqui de uma tradução ipisis literis, são apenas novos mesmos poemas. (WOJCIECHOWSKY 1991: 3)
}

Ou seja, não se trata de procurar traduzir os poemas segundo a concepção mais comum acerca da tradução: a versão literal. Pelo contrário, poemas bastante conhecidos no meio literário ganham uma nova roupagem, mais adequada à coloquialidade e à linguagem contemporâneas, processo que legitima o estilo de poesia de seus autores e revaloriza as obras já consagradas, por ora adormecidas devido a sua catalepsia.

Preferem operar estes poetas tradutores com o que chamam de livre adaptação, ou ainda, recriação/síntese. Trata-se de uma maneira diferente de traduzir, que, todavia, não deve ser vista como desleixo ou incapacidade artística, mas como uma vontade de recriar o poema nos trópicos, adequandoo ao vocabulário e aos valores da cultura recente, além de propor-lhe outra versão. São "novos mesmos poemas" de Baudelaire, Dante, Yeats, Poe, Mickiewicz, Shakespeare e, ressalte-se, Camões.

Todavia, a escolha dos termos, bem como a modulação da voz poética, miram para o vocabulário coloquial - às vezes chulo -, para uma poesia muito próxima à poesia marginal da década de 1970; à qual se incorporam o experimentalismo e a irreverência. 


\section{A tradução como legitimação e aperfeiçoamento da prática poética}

Traduzir poemas é um ofício muitas vezes legitimador da prática poética. Em termos de poetas brasileiros, são vários os exemplos de tal ofício, se pensarmos na obra de Bandeira, João Cabral, os Concretistas, José Paulo Paes, para ficarmos no Modernismo. Através da escolha de seu rol de autores, os poetas-tradutores estabelecem um diálogo entre sua obra e as leituras que a engendram, ou pelo menos, parte desta conversa, sempre em aberto.

Não é diferente o caso local, em que os autores-catalépticos revisitam seus mortos-vivos com o intuito de recriar os poemas que lhes agradam ou agradaram a suas leituras.

Nesse sentido, o Baudelaire da “Alma do Vinho" fica mais próximo do bar do que do ambiente literário: “Não é mole aguentar no lombo o sol rachando, / montanha de suor e mal trato tamanho, / pra me parir, beber e sair tropeçando, / esquecido de que subo mais se sou de antanho." (WOJCIECHOWSKY 1991: 42) Esta segunda estrofe, à luz de outras versões para o poema, como a de Ivan Junqueira, poderia soar estranha para muitos, todavia, não é este o escopo que norteia esta análise, visto que não era intenção dos tradutores, desde o início da obra, preservar Baudelaire no círculo literário do qual faz parte, em seu tempo e lugar específicos. Em vez disso, a "brincadeira" acontece em torno da suposta conversa entre a alma de Baco e o bêbado do poema original, a qual está marcada, desde a primeira estrofe, pela escolha linguística de termos atuais e comuns ao universo da embriaguez: “O espírito de Baco, exalando pelo gargalo, / bafejou: 'bebum, a sua saúde é minha alegria./ tirou a tampa, agora engula até o regalo, / mesmo de língua enrolada serei tua melodia.'” (WOJCIECHOWSKI 1991: 42)

Transcrevo a tradução de Ivan Junqueira, da mesma estrofe, para que o cotejo se faça mais claro: “A alma do vinho, certa tarde, nas garrafas / 
cantava: 'Homem, elevo a ti, que me és tão caro, / no cárcere de vidro e lacre em que me abafas, / um canto de luz e fraterno amparo!'” (JUNQUEIRA 1985: 377)

Em outro momento, no soneto "O Vinho dos Amantes", também de Baudelaire, o eu lírico propõe a entrega ao vinho como um convite ao devaneio, ao delírio que possibilitará a comunhão paradisíaca dos amantes. $\mathrm{Na}$ versão cataléptica, tal entrega também se verifica, porém a recriação/síntese dos autores opta pelo trocadilho onomatopeico, carregado de humor, que sugere o enlace amoroso, ou ainda, a embriaguez conciliada à sedução: “o paraíso já era aqui e paralelamente / em outro entramos como um só/ ic! epa! ops! rum... rum... ã? ó!” (WoJCIECHOWSKI 1991: 41) Na versão cataléptica, nota-se a diferença de tom, caracterizada por uma escolha vocabular mais próxima de uma atitude alcoólica menos comedida. É claro que há disparidade com o original, ou ainda, com as demais traduções do poema, porém o jogo em torno do tema amoroso, os termos coloquiais, o tom sensual não vêm diminuir a obra do poeta francês, mas atualizá-la. Com que direito? Com o de leitor, no mínimo, ou melhor, o de primeiro leitor - que é o tradutor - aliado ao direito de artista - o de criar com olhos livres, como salientava Mario de Andrade, no início do Modernismo, do qual as inovações acima são herdeiras.

Há muito se tem discutido sobre o ofício do tradutor, geralmente legado ao desprezo e a uma importância secundária na obra, não fazendo parte desta. Todavia, é por meio da tradução que a obra nos chega; então se aceite ou não, ao lermos a versão para nossa língua, estamos diante de certa originalidade, exercida pelo indivíduo que traduz em outro idioma, alicerçado na leitura que fez do original e, ainda, pelo modo como pôde apreender o jogo entre significantes e significados. Ao ler o poema na língua de origem, o leitor (tradutor) contempla não só os sentidos possíveis do texto; mas o som, a métrica, a estrofação, a escolha vocabular, entre outros estratos, que acabam por orientar a sua leitura e, posteriormente, sua prática.

Traduzir seria para o poeta uma maneira de "reencontrar os seus", 
(re)conhecendo no outro certas concepções ideológico-estéticas que dimensionam e redirecionam o seu trabalho. Há eco dos cantares de Pound na teoria da Poesia Concreta; de certa forma, é o que propõem estas versões catalépticas: recriações-síntese que se miram nos "exemplos" conhecidos da literatura mundial.

\title{
3. A livre-adaptação e a poesia contemporânea
}

A livre-adaptação enquanto projeto de tradução impele os autores a adequar os poemas às suas concepções de poesia. De certo modo, recriam os originais - ou mesmo as traduções dos originais - no estilo poético em que acreditam, por um lado por estarem atrelados ao Rock, ao fanzine, à obra leminskiana; por outro por pertencerem a uma época caracterizada pela mescla de estilos, visível na poética nacional do período. ${ }^{2}$

Heloísa Buarque de Hollanda, na antologia Esses Poetas, publicada na década de 1990, delineia este quadro, quando propõe que

\begin{abstract}
A poesia 90 circula, portanto, com tranquilidade e firmeza, por vários registros, revelando um domínio seguro da métrica, da prosódia, das novas tecnologias. [...] Em vez de fechar possibilidades, o poeta agora compromete-se com a ampliação de seus recursos de expressão, tornando este compromisso a marca e o avanço da literatura anos 90 . O novo, mais uma vez, é a originalidade na articulação, a afirmação de um desenho competente, a reinvenção experimental e criativa da tradição literária. (HoLLANDA 2001: 17).
\end{abstract}

Não é diverso o caso local, dado que há uma nova articulação nesta maneira de traduzir a tradição literária em outro contexto cultural. À medida

2 Afirmo isto, pensando em poemas de Augusto Massi, Arnaldo Antunes, Antonio Cícero, Josely V. Baptista, entre outros. 
que o ofício se consuma vão se revelando algumas marcas inerentes ao estilo dos autores, como a coloquialidade, a irreverência temática e linguística, a experimentação poética, mas sem desprezar, ou mesmo, negar as obras que, de certa maneira, apetecem a seus autores.

Ao traduzirem, estabelecem um diálogo não só cultural, mas dinâmico, porque enriquecem suas leituras de poesia, passando a perceber outras formas de compor, outros estratos poéticos, outras imagens e intenções artísticas - diálogo fecundo por natureza.

Visto que não há gênio sem labor, e que cada ser humano traz consigo enquanto leitor um horizonte de leituras, o contato com o "outro" intensifica o olhar para o "mesmo". Vê-se tal assertiva no poema de Poe, O Corvo, reproduzido em parte abaixo, no qual houve a intenção de se manter o refrão de modo que se preservasse nesta versão muito daquilo que the é peculiar e essencial, impondo ao tradutor o operar e compor de acordo com a intenção primeira do autor. Todavia, ao fazê-lo, mescla-se em meio a esta "obrigação" a originalidade por meio da recriação/síntese, principalmente em termos como "bêbado como sempre", "escriba extravagante", "berrei feito um possesso, / mas sem ignorar O Processo". Há aí o estabelecimento de um jogo estético em que a fronteira semântico-literária é superada e mantida:

Num dia desses

No exato momento do último instante,

Eu, bêbado como sempre, Num sonho de escriba extravagante, Delirava às vezes demais.

\section{$[\ldots]$}

'Aguenta as pontas um pouco mais.'

Berrei feito um possesso, Mas sem esquecer 0 Processo Que me acelerava o coração Me enervando ainda mais. 
Matando cachorro a grito,

Meto a mão na maçaneta

E só a noite testemunha o que fui capaz:

Deixar o bem ouvido pelo maldito?

Isso nunca, jamais.'(WOJCIECHOWSKI 1991: 52).

Sustentam estas impressões os agradecimentos feitos pelos autores nos créditos que abrem o livro, nos quais se pode perceber o cruzamento de leituras que antecederam a criação do poema, afinal os autores mencionam sua "dívida" para com "Machado de Assis, Fernando Pessoa e Emílio de Menezes, que não nos deixaram cair em tentação de fazer apenas mais uma tradução" (WOJCIECHOWSKI 1991: 4), ou seja, queriam os autores preservar a ideia e alguns recursos estilísticos já adotados por outros, mas sem prescindir de criar, de aproximar o poema à realidade mais próxima de seus possíveis leitores:

Ao ouvir palavras tão certeiras, recordei os bons tempos de rapaz.

'Eu também já fui assim, ô chupim, eco de todas as besteiras.'

E ele, na tampa: 'nunca mais.'(WOJCIECHOWSKI 1991: 54)

Vocábulos como "chupim", expressões como "na tampa", recolocam o poema num ambiente mais atualizado à década em que é produzido; sem perder, entretanto, seu mote: a conversa entre o eu lírico e a ave sombria.

Outro recurso estilístico bastante presente nestas traduções é o diálogo intertextual, com alguns trechos da música brasileira já enraizada na cultura popular: "O garçom faz o favor de me trazer depressa" ou "meu Deus do Céu, que palpite infeliz" na tradução do "Inferno" de Dante, denominada "Todo Inferno". (WOJCIECHOWSKI 1991: 9)

Também aparecem "Aos alquimistas estamos chegando" de Jorge Benjor, ou ainda, Lupicínio Rodriguez, na chegada do último círculo do 
inferno: "e agora se aproximando nosso maior tormento". (WOJCIECHOWSKI 1991: 18-19)

O humor e o deboche também pedem passagem:

Uma torre divisamos, em seguida, piscando aos viajantes: 'Lúcifer City'. Uma espécie de Las Vegas, sobre lava derretida.

Esta cidade incendiada é o limite disse-nos um belzebu fechando a entrada daqui para frente o fogo é irmão da dinamite.

$[\ldots]$

Descemos ao Círculo seguinte pela ordem. 'O Inferno tem a forma de um redemoinho, quanto mais se afunda mais os diabos podem'

Um cheiro pestilento mostrou-nos o caminho. 'O Sétimo Círculo tem três Giros: o primeiro é pra tirano, latrocida ou assassino, cujos crimes se pagam com martírios símiles: mergulhados em mar de sangue fervente, Tão quente que o recusam os vampiros.' (WOJCIECHOWSKI 1991: 13)

Repare-se que é mantido o esquema rímico, o enredo, a estrofação, acrescentando-lhes traços de contemporaneidade, pelo uso da linguagem coloquial, da gíria, do tom de deboche.

Há, então, um aproveitamento de certo dado cultural em nome da tradução transcultural, tornando o texto bastante plurissignificativo.

Chavões também são comuns: "Agüenta as pontas um pouco mais", em O Corvo; "matando medo a grito" trocadilho com "matando cachorro a grito", já exposto.

Outro estrato a mencionar é o didatismo oferecido ao leitor em 
virtude do uso de notas de rodapé que auxiliam e conduzem a leitura, principalmente àqueles que não tiveram contato com outra tradução da obra.

Assim, aparecem na tradução do "Inferno" de Dante várias notas: para o verso "entrada de cabeça na selva escura" há a nota "placa na saída do bar"; para "Dante fui, sou sua escolta" aparece a nota "no original, Virgílio era o guia de Dante", ou ainda, para o verso "Meu Deus do Céu, que palpite infeliz!!” a admiração pelo músico Noel Rosa : “Noel Rosa é eterno."(WOJCIECHOWSKI 1991: 9)

São estes alguns dos principais recursos, os quais também podem ser vistos nas outras criações destes poetas, o que marca uma das vertentes da poesia feita em Curitiba na década de 1990.

\subsection{Camões traduzido para o Português?}

O "Soneto XXXII" de Luis de Camões mostra o hiato entre o pensar e a subjetividade do ser que pensa sobre si. Escrito em português do século XVI, ele é revisitado na própria língua, não na forma de Soneto, prática em nada absurda se pensarmos que a evolução linguística é uma característica natural do idioma, dinamizada pelas escolhas que os falantes fazem dos vocábulos, pelas diversas relações com a fala, pelo choque com outras culturas, entre outros fatores.

Novamente aparece a liberdade na recriação/síntese dos autores. Entretanto a escolha dos termos se dá com maior acuidade, na intenção de se preservar um pouco do léxico português: 
Smaniotto, A. da R. - Os Catalépticos e Um Fausto - Novos Mesmos

Poemas

XXXII

Pensamento, meu caro pensamento, me convença

O que penso ser não é o que você pensa

Lembro de não pensar tal como antigamente

Contente de ter quem o tem tão descontente

No entanto, você vai e vem com este sorriso alegre

Que por si só não basta e a mim não serve

Nenhum me negue, se pensa em renegar-me

Estarei a postos para ajudar a despensar-me (WOJCIECHOWSKI 1991: 47).

Preservam-se, ainda, os jogos paronomásicos, ao gosto do bardo português. Uma vez que entendem a tradução como livre adaptação reescrevem o poema numa língua que se quer a mesma, mas é outra; recriando o poema, mas conferindo-lhe a certidão de origem.

\section{Um Fausto: livre-adaptação de Goethe}

Produzida dois anos mais tarde, entre 1993 e 1994, esta tradução prima pela participação de dois dos quatro autores presentes na obra Os Catalépticos: Thadeu Wojciechowski e Sérgio Viralobos. Também de caráter experimental - marca comum a estes autores - a proposta conserva um tom de reverência e deboche. Como no outro livro, a advertência irreverente já o apresenta:

“ De como Antonio Thadeu Wojciechowski e Sérgio Viralobos, mesmo sem entender bulhufas de alemão, fizeram esta livre-adaptação da obra de Goethe, sem prejudicar-lhe o gênio [grifo do autor deste artigo], conseguindo ainda, emprestar-lhe modernidade suficiente para os próximos mil anos e, além disso, propiciar ao povo alemão a oportunidade de uma nova e total tradução." (WOJCIECHOWSKI 1994: 3). 
Em termos comparativos, esta recriação se dá com maior liberdade em relação à obra original, pois o enredo da narrativa, em verso, parte de uma pressão do editor sobre o poeta, para que este componha uma obra e aí surge "Um Fausto". De novo, estão presentes a coloquialidade: "Dá um baita azar seduzir a mulherada" (WoJCIECHOWSKI 1994: 32); a irreverência: "Mefistófeles, quando quer, é gentleman doutorado, / só sendo de outro mundo pra bolar um plano tão bem traçado./ procurando paparicar as duas desmanchou-se em agrado ..." (WOJCIECHOWSKI 1994: 26); o termo chulo: "Nem fodendo, o diabo não faz nada de graça" (WOJCIECHOWSKI 1994: 19); e, principalmente, o humor:

\section{Margarida}

Henrique, jura por Deus que você não é ateu?

Fausto

De juras bastam as minhas de amor por você?

Margarida

Eu me refiro a um amor acima do meu e do teu.

\section{Fausto}

A bíblia torna descrente quem a sabe ler.

\section{Margarida}

Deus é uma figurinha difícil no seu álbum de mitologia?

(...)

\section{Margarida}

Falou tão bem quanto um padre, só que em outro tom.

\section{Fausto}

Lá me vem você com mais um lugar-comum.

\section{Margarida}

Tudo que mal se conhece parece bom. (WoJCIECHOWSKI 1994: 33-34).

O pacto com o Diabo, aqui, é em torno de um jogo passional de Fausto por uma passante, Margarida. À primeira vista, aos mais puristas, tal proposta de tradução poderia soar como um arremedo muito mal feito, uma grande deturpação. Pensar assim seria interromper o diálogo entre as obras, bem como a liberdade criadora que é conquista valorativa em arte desde o Modernismo. 
Ao contrário da obra de Goethe, esta versão suscita o riso mais do que a reflexão metafísica, mas é nesta dimensão que deve ser olhada: como uma diversão em torno do tema tão caro à literatura - o pacto com o Diabo que possui eco em tantas obras, mas sem diminuir a obra de origem que, ao ser espelho desta, continua a engendrar significados. O leitor fará suas escolhas: ler as duas versões e tantas outras, ou não ler nenhuma. Já o tradutor fez a sua: redisse aquilo que havia lido, mas do jeito que the coube; eis a literatura, ou ainda, tal concepção de tradução literária.

Composta de 48 páginas, a tradução ainda ganha outro aspecto de atualidade: surgem na página 41 reproduções de um suposto jornal " $O$ povo alemão", escritas em verso, as quais fazem referência ao assassinato do próprio filho por Margarida, em seguida o poema é retomado. De novo, há um diálogo com a contemporaneidade por meio da fusão da linguagem literária, jornalística, publicitária, ultimamente bastante exploradas.

\section{Sobre os autores}

A principal característica da geração de poetas OSS $^{3}$ é o experimentalismo. Seja na composição a quatro mãos, seja no desejo de uma nova ortografia da língua portuguesa, seja nas livres-adaptações, ou mesmo, nos poemas. Um pouco de herança do Rock misturada à espontaneidade, à ironia, ao humor, à contemporaneidade.

Seus autores - Marcos Prado, Thadeu Wojchiechowski, Sérgio Viralobos, Roberto Prado, aliados a colaboradores como Edson de Vulcanis, Edilson Del Grossi e Ubiratan de Oliveira, conciliaram criações poéticas com outras

3 Por geração de poetas OSS refiro-me à própria concepção que os autores têm de si. Em um livro dos autores aparece a seguinte definição: 'OSS: ossichinobu - vem do japonês. Pode ser traduzido como opa, e aí, oi, desculpe a porrada. [...] já em português imaginamos [grifo do autor deste artigo] que possa ser um anagrama de save our souls, o plural do artigo masculino plural os ...' Ou seja, a atitude irreverente está no cerne do grupo. 
linguagens artísticas locais, principalmente com a música.

Tem na sua formação o gosto pelos clássicos, mas a aversão a líderes. Misturam poesia concreta, poesia marginal e filmes B (de terror) nacionais, como os encenados por Zé do Caixão.

Embora atuantes desde 1978, na década de 1990 publicaram a maioria de seus livros. 


\section{Referências bibliográficas}

BaRTHES, R. O prazer do texto. 5. ed. São Paulo: Perspectiva, 1999.

BAUDELAIRE, Charles. As flores do mal: tradução e notas de Ivan Junqueira. Rio de Janeiro: Nova Fronteira, 1985.

Eco, U. Os limites da Interpretação. Tradução P. De Carvalho. São Paulo: Perspectiva, 1999.

Hollanda, Heloísa B. Esses Poetas: uma antologia dos anos 90. Rio de Janeiro: Aeroplano, 2001.

WojcIeCHOWskI, A. T. et al. Os Catalépticos. Curitiba: Lagarto Editores, 1991.

WojCIECHOWSKI, A. T.; VIRALOBOS, Sérgio; et al. Um Fausto. Curitiba: Lagarto Editores: 1994. 